\title{
Opioid Free Anesthesia in Laparoscopic Cholecystectomy (Comparative Clinical Study)
}

\author{
Osama Helal Ahmed ${ }^{1}$, Tawfik Mohammed Noor El-Din ${ }^{2}$, \\ Waheed Mohamed Ali ${ }^{1}$, Zeinab Mustafa Sayed ${ }^{3}$
}

${ }^{1}$ Department of Anesthesiology \& Intensive Care Faculty of Medicine, Al Azhar University (Assuit), ${ }^{2}$ Department of Anesthesiology \& Intensive Care, Faculty of Medicine, Al Azhar University (Cairo), ${ }^{3}$ Department of Anesthesiology \& Intensive Care, Faculty of Dentistry and Oral Medicine, South Valley University. Corresponding author: Zeinab Mustafa Sayed, Tel.: 0965211281; E-mail: zainab.mustafa@dent.svu.edu.eg

\begin{abstract}
Background: Opioid Free Anesthesia aims to avoid perioperative opioids, instead uses adjuvant agents for their opioid-sparing effect which could also affect recovery rates and hospital length of stay (LOS).

Patients and Methods: This prospective, randomized, single-blinded clinical study included 62 patients aged between 21 to 50 years, scheduled for LC. Group OA $(n=31)$ received OA with fentanyl as the main anesthetic adjuvant and peri-operative analgesic. Group OFA $(n=31)$ received OFA with dexmedetomidine, ketamine, and paracetamol as an anesthetic adjuvant and peri-operative analgesics. The intraoperative assessment included HR, systolic, diastolic and mean BP, the need for rescue analgesia or ephedrine. The postoperative assessment included the same values plus VAS score, Aldrete score, duration of stay in PACU, the incidence of side effects and complications and hospital LOS.

Results: No significant difference between both groups regarding intraoperative hemodynamic values. In the group, OA 22 patients $(70.9 \%$ ) required intraoperative rescue analgesia (with mean dose $55.6 \pm 37.4 \mu \mathrm{g}$, median $70 \mu \mathrm{g}$ and highest dose of $100 \mu \mathrm{g})$ compared to none in group OFA. In the group, OA $10(32.3 \%)$ patients had PONV compared to $3(9.7 \%)$ patients from group OFA which was statistically significant (P-value 0.033$)$. No significant difference between both groups regarding postoperative VAS score, analgesic requirement, discharge time from PACU or LOS. Conclusions: The study showed that OFA was as effective as OA in maintaining intraoperative hemodynamic stability although group OFA showed the lower need for intraoperative analgesia. OFA also showed a significant reduction of incidence of PONV compared to group OA.
\end{abstract}

Keywords: OFA, Opioid, Fentanyl, Dexmedetomidine, Ketamine, Multimodal, Analgesia, PONV, LOS.

\section{INTRODUCTION}

The well-known side effects of opioids such as respiratory depression, sedation, nausea/vomiting, Constipation, and ileus have become an increasingly major medical nuisance that more importantly can lead to significant morbidity and mortality ${ }^{(\mathbf{1})}$. Besides, short-acting opioids usually administered perioperatively to produce hemodynamical stability and optimum analgesic levels, may lead to acute opioid-induced tolerance and hyperalgesia ${ }^{(2)}$.

Furthermore, evidence showed that despite using conventional multimodal approaches that involve opioids, postoperative pain and postoperative nausea and vomiting (PONV) are still common complaints reported after laparoscopic cholecystectomy (LC) ${ }^{(\mathbf{3}, \mathbf{4})}$.

Opioid Free Anesthesia (OFA) was introduced as an alternative solution that aims to achieve stress-free anesthetics while avoiding using perioperative systemic, neuraxial, or intracavitary opioid altogether. Instead, a multimodal approach of sympatholytic drugs and non-opioid analgesics have shown it can lead to intraoperative hemodynamical stability with reducing the need for further analgesics and also avoid the use of any opioid postoperatively as well ${ }^{(5)}$.

Therefore, we hypothesized in this study that an opioid-free anesthetic regimen consisting of both dexmedetomidine and ketamine infusions, along with intravenous (IV) paracetamol, and magnesium as a rescue co-analgesic, is an effective anesthetic technique for patients undergoing LC, compared to the standard opioid-based anesthetic regimen regarding intraoperative hemodynamic stability, postoperative pain intensity, discharge time from post-anesthetic care unit (PACU), the incidence of side effects in the early postoperative period and length of stay in hospital (LOS).

\section{AIM OF THE WORK}

This prospective, randomized, single-blinded clinical study aimed to compare OFA to the conventional general anesthesia (with opioids) as regarding: Primary outcome measure: Hemodynamic stability intraoperatively as a reflection of the adequacy of analgesia, speed of recovery, postoperative analgesia, discharge time from PACU and LOS.

2Secondary outcome measures: The incidence of side effects and complications postoperatively (PONV, pruritis and respiratory depression).

\section{PATIENTS AND METHODS}

This prospective, randomized, single-blinded clinical study was designed to include 62 patients from both gender male and female aged between 21 to 50 years, with an ASA physical status of I and II, who were scheduled for LC. 
Exclusion Criteria included: Morbidly obese patients (BMI > 30). •Pregnant or nursing woman. Patients currently on anti-hypertensive drugs. Patients currently taking opioid, NSAID or paracetamol. -Patients with allergies to study medication. Patients with obstructive sleep apnea syndrome (OSAS). -Patients with unstable cardiorespiratory disorders. -Patients with hepatic and renal insufficiency.

After using computer-generated opaque sealed envelopes, 62 Patients scheduled for elective laparoscopic cholecystectomy were randomly assigned into two groups: - Group OA $(n=31)$ : received general anesthesia with propofol, isoflurane and muscle relaxant (rocuronium), and with fentanyl as the main anesthetic adjuvant and peri-operative analgesic. 28 - Group OFA ( $\mathrm{n}=31)$ : received opioidfree anesthesia with propofol, isoflurane and muscle relaxant (rocuronium), and with dexmedetomidine, ketamine and paracetamol as an anesthetic adjuvant and peri-operative analgesics.

Anesthesia management: For all patients, history was taken and clinical examination was done. Inside the operating theatre (OT), all patients had standard monitoring parameters including; continuous electrocardiogram (ECG), non-invasive blood pressure (NIBP), and pulse oximetry for pulse and oxygen saturation, and capnography. An intravenous (IV) line was placed, then patients from both groups were pre oxygenated and anesthesia was induced with propofol (Diprivan $10 \mathrm{mg} / \mathrm{ml} \mathrm{1 \% ,} \mathrm{Astra} \mathrm{Zeneca)} \mathrm{1-2}$ $\mathrm{mg} / \mathrm{kg} \mathrm{IV}$, and rocuronium (Esmeron 50mg/5ml, N.V Organon) $0.5-1.0 \mathrm{mg} / \mathrm{kg} \mathrm{IV}$, to facilitate endotracheal intubation. After induction and intubation, muscle relaxation was maintained with IV boluses of rocuronium 10-20 $\mathrm{mg}$ to provide optimal surgical conditions and general anesthesia (GA) was maintained with inhalation anesthetics (isoflurane) at a MAC of $1.2 \%$. At the end of the surgery, muscle relaxation was reversed with neostigmine (up to $5 \mathrm{mg}$ ) and atropine $0.2-0.8 \mathrm{mg}$.

In the OA group: Fentanyl (Fentanyl Hameln $0.1 \mathrm{mg} / 2 \mathrm{ml}$, Sunny pharmaceutical) $1 \mathrm{ug} / \mathrm{kg} \mathrm{IV}$, was administered with the induction of GA and intermittent boluses of fentanyl was given at the anesthesia provider's discretion when needed to maintain the change in hemodynamics within $20 \%$ of the baseline.

In the OFA group: A loading dose of dexmedetomidine (Precedex $200 \mu \mathrm{g} / 2 \mathrm{ml}$, Hospira, inc, Lake forest USA) $1 \mu \mathrm{g} / \mathrm{kg} \mathrm{IV}$, was given before induction of GA, diluted to a total volume of $10 \mathrm{~mL}$ and infused over $10 \mathrm{~min}$. Then, an IV infusion of dexmedetomidine was maintained at a rate of 0.5 $\mu \mathrm{g} / \mathrm{kg} / \mathrm{h}$. An IV infusion of ketamine (Ketamin Inresa $50 \mathrm{mg} / \mathrm{ml}$, Inresa 29 Arzneimittel GmbH Freiburg) $0.1-0.3 \mathrm{mg} / \mathrm{kg} / \mathrm{h}$, and a loading dose of paracetamol
(Injectmol 1g/100ml, Amriya Pharm Ind.) 10-15 $\mathrm{mg} / \mathrm{kg}$ was also given with induction. Boluses of $\mathrm{Mg}$ sulphate (Magnisol 0.5mg/5ml, Memphis) $50 \mathrm{mg} / \mathrm{kg}$ were given as a rescue co-analgesic and might be used as maintenance with a dose of $6-20 \mathrm{mg} / \mathrm{kg} / \mathrm{h}$ as IV continuous infusion if needed. In case of hypotension (more than 20\% decrease than baseline). Boluses of ephedrine (Ephedrine U.S.P.27, 2mg/1ml, Misr CO) 3-9 mg per dose, were given to correct over sympatholysis and to maintain the change in hemodynamics within $20 \%$ of baseline. Both dexmedetomidine and ketamine infusion was gradually decreased after removal of the gall bladder and stopped completely at the end of surgery.

Neuromuscular blockade was reversed by IV neostigmine (Neostigmine Methylsulphate $0.5 \mathrm{mg}$, Amriya Pharm Ind.) at a dose of $0.03 \mathrm{mg} / \mathrm{kg}$, along with atropine (Atropine sulfate $0.1 \%$, Memphis) at a dose of $0.01 \mathrm{mg} / \mathrm{kg}$. Heart rate, systolic BP, diastolic $\mathrm{BP}$ and mean arterial BP were recorded just before induction of anesthesia, at baseline, immediately before and post-induction, after intubation before surgical intervention, at the beginning of surgical intervention, before abdominal insufflation, post insufflation, every $10 \mathrm{~min}$ during surgery, after abdominal deflation, before and after extubation. Then, continued recording every $15 \mathrm{~min}$ in PACU along with visual analog score (VAS) and analgesic requirements until criteria of discharge from PACU were achieved by reaching modified Aldrete score $\geq 9$.

\section{Postoperative management in PACU:}

HR, systolic BP, Diastolic BP and mean arterial BP were recorded as mentioned before. The level of pain was assessed using VAS and analgesics were given at score $>3$. Postoperative pain was treated with IV paracetamol $(1 \mathrm{~g})$ and IV ketorolac $(30 \mathrm{mg})$ every $6 \mathrm{~h}$ for the first $24 \mathrm{~h}$ in both groups.

In the OA group, patients still experiencing postoperative pain received IV fentanyl $1-2 \mu \mathrm{g} / \mathrm{kg}$ guided by VAS scores. In the OFA group, dexmedetomidine and ketamine infusions were allowed to continue in the PACU depending on the severity of pain guided by VAS scores.

Complications as PONV, pruritis, respiratory depression were recorded and treated accordingly. The duration of stay in PACU was determined when criteria of discharge were achieved according to the Modified Aldrete Scoring System, which means when the patient's modified Aldrete score was $\geq 9$. Hospital LOS was recorded and was defined as the time from the end of surgery to the time discharge criteria were met. Criteria for discharging patients required that patients have VAS score below 4, tolerate oral diet, can self-ambulate, and have no postoperative complications.

Demographic data as age, sex, and weight, HR, systolic BP, diastolic BP and MAP readings, VAS \& 
Aldrete scores, analgesic requirement, side effects, complications, time spent in PACU and length of hospital stay all were timely recorded.

Data analysis: was carried out using IBM SPSS Statistics version 20 (SPSS Inc., Chicago, IL, USA). Categorical data were presented as frequencies and percentages, while Chi-square tests were used for comparison between groups. Continuous data were reported as mean \pm standard deviations and tested for normality using the Shapiro-Wilkes test. Where continuous data were normally distributed, the Student's T-test was used for comparisons between groups; where data were non-normally distributed, the Mann Whitney test was used. Changes in intraoperative hemodynamics among the two groups were analyzed with one-way repeated measures ANOVA. To examine interactions between time and groups the Two-way repeated-measures ANOVA with "group" (between-subjects variables: OA versus OFA) and "time" (within-subjects variable: intraoperative assessment points), as the main factors. P-value $<0.05$ was considered statistically significant.

\section{RESULTS}

\section{Regarding general characteristics of studied} groups:

There was no statistically significant difference between the two groups regarding age, sex, weight, and duration of the operation. (Table 1).

Table (1) General characteristics of studied group $(\mathbf{n}=62)$

\begin{tabular}{|c|c|c|c|c|}
\hline \multicolumn{2}{|c|}{ Variable } & $\begin{array}{c}\text { OA } \\
\mathbf{N}=\mathbf{3 1}\end{array}$ & $\begin{array}{c}\text { OFA } \\
\mathrm{N}=31\end{array}$ & $\begin{array}{c}\text { P- } \\
\text { value }\end{array}$ \\
\hline \multicolumn{2}{|c|}{ Age (Ys) } & $37.7 \pm 4.5$ & $39.1 \pm 5.3$ & $0.247^{a}$ \\
\hline \multirow{2}{*}{ Sex } & Male & $14(45.2 \%)$ & $\begin{array}{l}13 \\
(41.9 \%)\end{array}$ & \multirow{2}{*}{$0.798^{b}$} \\
\hline & Female & $17(54.8 \%)$ & $\begin{array}{l}18 \\
(58.1 \%)\end{array}$ & \\
\hline \multicolumn{2}{|c|}{ Weight (Kg) } & $76.5 \pm 9.6$ & $72.1 \pm 6.8$ & $0.138^{a}$ \\
\hline \multicolumn{2}{|c|}{$\begin{array}{l}\text { Operation } \\
\text { duration (min) }\end{array}$} & $\begin{array}{l}65.3 \pm \\
15.7\end{array}$ & $\begin{array}{l}60.2 \pm \\
13.7\end{array}$ & $0.178^{a}$ \\
\hline
\end{tabular}

Regarding intraoperative assessment: Intraoperative heart rate changes in studied groups:

The heart rate was significantly lower in group OFA compared to the OA group along with the following points: before induction, after induction, before intervention, before insufflation, after deflation, and after extubation. The heart rate assessment during operation by repeated measure one-way ANOVA among studied groups shows a significant difference in heart rate intraoperatively in each group separately; as for both groups P-value <0.001. Two-way ANOVAs with Time (12 points of assessment) and Group (OA or OFA) as main factors showed that there was a significant Time $\mathrm{X}$ group interaction ( $\mathrm{P}$-value < 0.001). (Table 2, Figure 1).

Table (2): Intraoperative heart rate changes in studied groups:

\begin{tabular}{|c|c|c|c|}
\hline HR (b/min) & $\begin{array}{l}\mathbf{O A} \\
\mathrm{N}=31\end{array}$ & $\begin{array}{l}\text { OFA } \\
\mathbf{N}=\mathbf{3 1} \\
\end{array}$ & $\begin{array}{l}\text { P-value } \\
a\end{array}$ \\
\hline Baseline & $\begin{array}{l}88.2 \pm \\
11.6\end{array}$ & $87.2 \pm 11.3$ & 0.716 \\
\hline Before induction & $\begin{array}{l}94.4 \pm \\
16.6 \\
\end{array}$ & $77.0 \pm 18.5$ & $<0.001^{*}$ \\
\hline After induction & $\begin{array}{l}82.2 \pm \\
13.3 \\
\end{array}$ & $70.6 \pm 17.7$ & $0.005^{*}$ \\
\hline After intubation & $97.0 \pm 6.7$ & $92.0 \pm 16.9$ & 0.129 \\
\hline Before intervention & $85.2 \pm 5.9$ & $80.5 \pm 10.9$ & $0.042 *$ \\
\hline $\begin{array}{l}\text { Beginning } \\
\text { intervention }\end{array}$ & $84.4 \pm 9.8$ & $82.5 \pm 9.6$ & 0.436 \\
\hline Before insufflation & $\begin{array}{l}86.5 \pm \\
12.4\end{array}$ & $79.7 \pm 8.2$ & $0.013^{*}$ \\
\hline Post insufflation & $\begin{array}{l}88.6 \pm \\
11.4 \\
\end{array}$ & $86.5 \pm 18.6$ & 0.601 \\
\hline HR every $10 \mathrm{~min}$ & $83.4 \pm 8.2$ & $78.6 \pm 14.1$ & 0.109 \\
\hline After deflation & $80.6 \pm 7.8$ & $74.3 \pm 11.8$ & $0.015^{*}$ \\
\hline Before extubation & $83.6 \pm 8.3$ & $81.8 \pm 13.9$ & 0.538 \\
\hline After extubation & $91.8 \pm 10.2$ & $85.4 \pm 14.5$ & $0.048 *$ \\
\hline One-way ANOVA & $\begin{array}{l}\mathrm{P}<0.001^{*} \\
\mathrm{~F}=13.6\end{array}$ & $\begin{array}{l}\mathrm{P}<0.001 * \\
\mathrm{~F}=10.7\end{array}$ & \\
\hline Two-way ANOVA & \multicolumn{2}{|c|}{$\mathrm{P}<0.001^{*} \quad \mathrm{~F}=6.6$} & \\
\hline
\end{tabular}




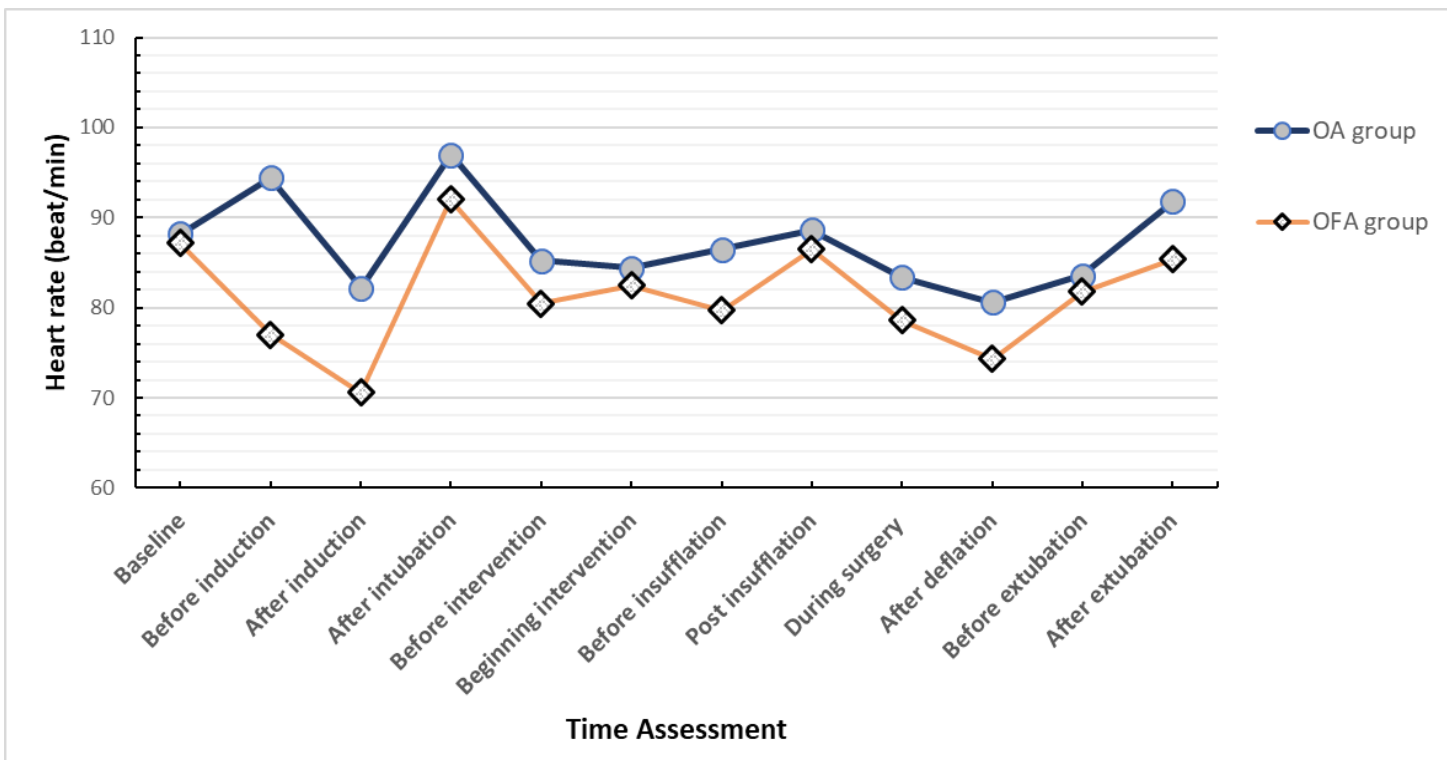

Figure (1) Intraoperative heart rate changes for studied groups

Intraoperative systolic blood pressure changes in studied groups:

The intraoperative change of systolic BP was lower in the OFA group compared to the OA group along with the following points: before induction, after induction, before intervention, at beginning of intervention, after deflation and after extubation and all of these differences were statistically significant. The systolic BP assessment during the operation by repeated measure one-way ANOVA among studied groups shows significant difference intraoperatively in each group separately; as for both groups P-value $<0.001$. $\mathrm{T}$

wo-way ANOVAs with Time (12 points of assessment) and Group (OA or OFA) as main factors showed that there was a significant Time $\mathrm{X}$ group interaction (P-value < 0.001). (Table3, Figure 2).

Table (3) Intraoperative systolic blood pressure changes in studied groups

\begin{tabular}{|c|c|c|c|}
\hline Systolic BP & $\begin{array}{c}\text { OA } \\
\mathbf{N}=\mathbf{3 1}\end{array}$ & $\begin{array}{c}\text { OFA } \\
\mathrm{N}=31\end{array}$ & P-value \\
\hline Baseline & $120.2 \pm 10.2$ & $122.9 \pm 7.2$ & 0.294 \\
\hline Before induction & $127.3 \pm 13.4$ & $110.7 \pm 13.9$ & $<0.001 *$ \\
\hline After induction & $112.5 \pm 14.9$ & $103.1 \pm 14.5$ & $0.014 *$ \\
\hline After intubation & $118.5 \pm 15.7$ & $114.3 \pm 11.0$ & 0.225 \\
\hline Before intervention & $107.2 \pm 8.1$ & $96.5 \pm 16.9$ & $0.002 *$ \\
\hline Beginning intervention & $111.9 \pm 7.1$ & $101.1 \pm 10.7$ & $<0.001 *$ \\
\hline Before insufflation & $106.4 \pm 4.9$ & $104.2 \pm 5.3$ & 0.096 \\
\hline Post insufflation & $114.3 \pm 8.2$ & $111.3 \pm 6.5$ & 0.117 \\
\hline SBP every $10 \mathrm{~min}$ & $109.4 \pm 8.9$ & $107.1 \pm 5.3$ & 0.214 \\
\hline After deflation & $106.2 \pm 5.9$ & $99.4 \pm 9.8$ & $0.001 *$ \\
\hline Before extubation & $113.1 \pm 14.0$ & $108.3 \pm 7.7$ & 0.102 \\
\hline After extubation & $117.6 \pm 5.2$ & $110.5 \pm 15.8$ & $0.020^{*}$ \\
\hline One-way ANOVA & $\mathrm{P}<0.001 * \quad \mathrm{~F}=36.6$ & $\mathrm{P}<0.001 *$ & \\
\hline Two-way ANOVA & $\mathrm{P}<0.001 *$ & & \\
\hline
\end{tabular}




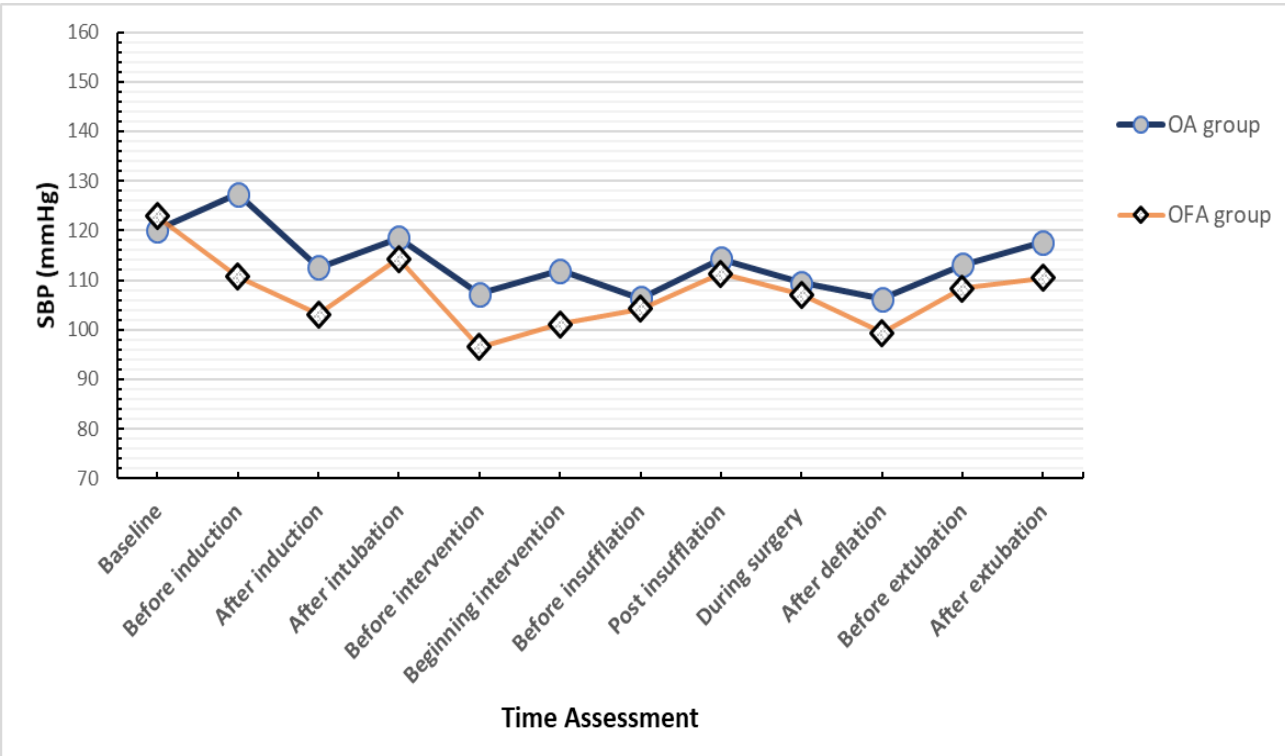

Figure (2) Intraoperative systolic blood pressure changes for studied groups

Intraoperative diastolic blood pressure changes in studied groups:

The intraoperative change of diastolic BP was lower in the OFA group compared to the OA group along with the following points: before induction, after induction, before intervention, at beginning of intervention, after deflation and after extubation, and all these differences were statistically significant. The diastolic BP assessment during the operation by repeated measure one-way ANOVA among studied groups shows significant difference intraoperatively in each group separately; as for both groups P-value $<0.001$. Two-way ANOVAs with Time (12 points of assessment) and Group (OA or OFA) as main factors showed that there was a significant Time $X$ group interaction (P-value < 0.001). (Table4, Figure 3).

Table (4) Intraoperative diastolic blood pressure changes in studied groups

\begin{tabular}{|l|l|l|l|}
\hline Diastolic BP & $\begin{array}{l}\text { OA } \\
\text { N=31 }\end{array}$ & $\begin{array}{l}\text { OFA } \\
\text { N= 31 }\end{array}$ & P-value $^{a}$ \\
\hline Baseline & $73.8 \pm 6.7$ & $75.1 \pm 7.2$ & 0.062 \\
\hline Before induction & $78.6 \pm 8.8$ & $72.8 \pm 7.8$ & $0.008^{*}$ \\
\hline After induction & $70.1 \pm 10.3$ & $62.4 \pm 11.5$ & $0.007^{*}$ \\
\hline After intubation & $71.5 \pm 9.3$ & $69.5 \pm 7.8$ & 0.356 \\
\hline Before intervention & $64.7 \pm 7.9$ & $56.5 \pm 9.8$ & $0.001^{*}$ \\
\hline Beginning intervention & $65.6 \pm 6.4$ & $58.6 \pm 10.6$ & $0.002^{*}$ \\
\hline Before insufflation & $65.2 \pm 6.9$ & $62.6 \pm 10.0$ & 0.232 \\
\hline Post insufflation & $70.1 \pm 8.6$ & $69.8 \pm 9.8$ & 0.913 \\
\hline DBP every 10 min & $66.4 \pm 8.5$ & $65.6 \pm 12.3$ & 0.766 \\
\hline After deflation & $61.7 \pm 8.1$ & $53.9 \pm 10.7$ & $0.002^{*}$ \\
\hline Before extubation & $68.1 \pm 8.0 \quad 65.6 \pm 16.4$ & 0.458 \\
\hline After extubation & $70.6 \pm 8.8$ & $64.1 \pm 16.2$ & $0.049^{*}$ \\
\hline One-way ANOVA & $\mathrm{P}<0.001^{*} \quad \mathrm{~F}=29.1$ & $\mathrm{P}<0.001^{*} \quad \mathrm{~F}=13.6$ & \\
\hline Two-way ANOVA & $\mathrm{P}<0.001^{*} \quad \mathrm{~F}=6.9$ & & \\
\hline
\end{tabular}

* Significant p-value.

a Student's T-test was used. 


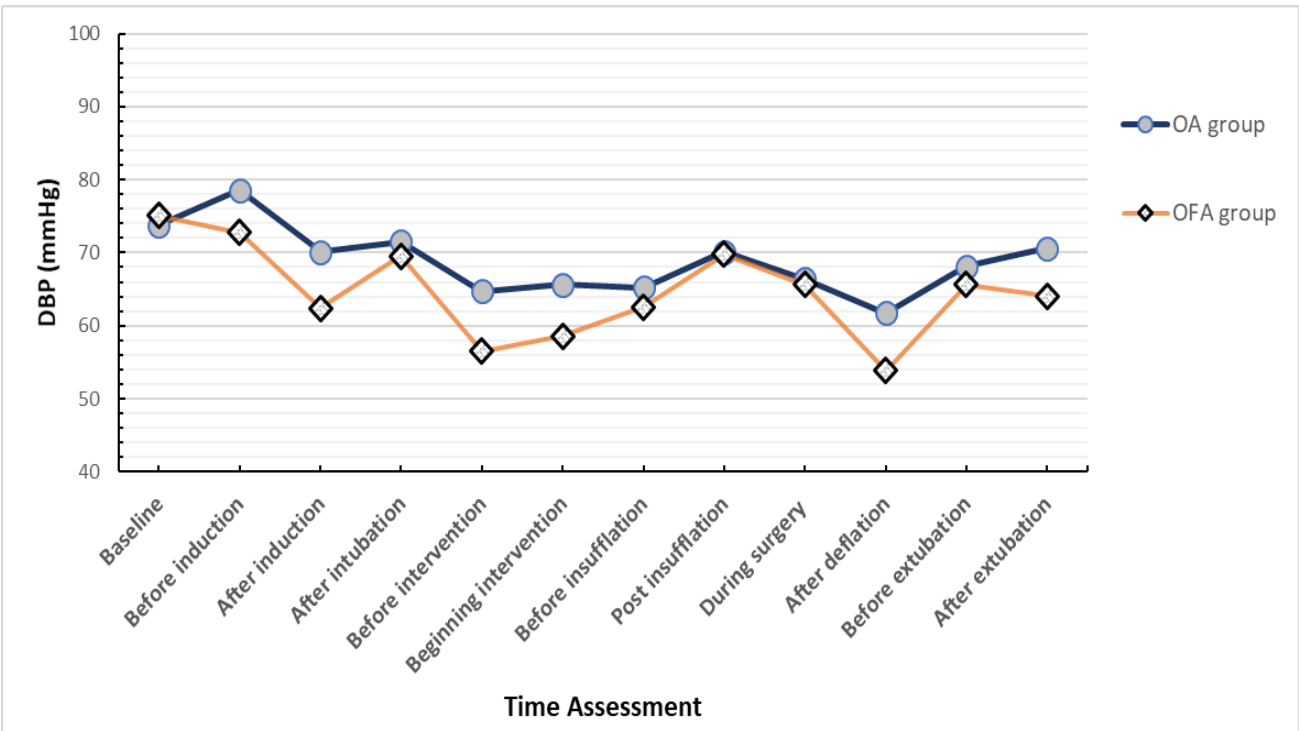

Figure (3) Intraoperative diastolic blood pressure changes for studied groups

Intraoperative mean blood pressure changes in studied groups

The MAP was lower in the OFA group compared to the OA group along with the following points: before induction, after induction, before intervention, at beginning of intervention, after deflation and after extubation and all these differences were statistically significant. The MAP assessment during the operation by repeated measure one-way ANOVA among studied groups shows significant difference intraoperatively in each group separately; as for both groups $\mathrm{P}$-value $<0.001$.

Two-way ANOVAs with Time (12 points of assessment) and Group (OA or OFA) as main factors showed that there was a significant Time $\mathrm{X}$ group interaction (P-value < 0.001). (Table 5, Figure 4).

Table (5) Intraoperative mean blood pressure changes in studied groups

\begin{tabular}{|l|l|l|l|}
\hline MAP & $\begin{array}{l}\text { OA } \\
\text { N= 31 }\end{array}$ & $\begin{array}{l}\text { OFA } \\
\text { N= 31 }\end{array}$ & P-value $^{a}$ \\
\hline Baseline & $93.2 \pm 9.3$ & $92.4 \pm 7.2$ & 0.706 \\
\hline Before induction & $94.1 \pm 7.7$ & $85.2 \pm 4.5$ & $<0.001^{*}$ \\
\hline After induction & $84.5 \pm 10.9$ & $76.2 \pm 5.7$ & $<0.001^{*}$ \\
\hline Befor intubation & $85.5 \pm 10.7$ & $84.7 \pm 9.0$ & 0.759 \\
\hline Beginning intervention & $79.1 \pm 8.3$ & $72.1 \pm 12.6$ & $0.013^{*}$ \\
\hline Before insufflation & $80.5 \pm 5.8$ & $74.2 \pm 11.2$ & 0.007 \\
\hline Post insufflation & $78.4 \pm 6.3$ & $76.2 \pm 11.4$ & 0.344 \\
\hline MBP every 10 min & $86.6 \pm 8.9$ & $84.3 \pm 8.9$ & 0.315 \\
\hline After deflation & $83.1 \pm 8.1$ & $79.3 \pm 9.7$ & 0.104 \\
\hline Before extubation & $76.9 \pm 11.7$ & $67.0 \pm 8.3$ & $<0.001^{*}$ \\
\hline After extubation & $85.5 \pm 10.5$ & $81.1 \pm 8.3$ & 0.177 \\
\hline \hline One-way ANOVA & $86.9 \pm 9.5$ & $79.8 \pm 17.8$ & $0.049^{*}$ \\
\hline \hline Two-way ANOVA & $\mathrm{P}<0.001^{*} \mathrm{~F}=33.7$ & $\mathrm{P}<0.001^{*} \quad \mathrm{~F}=17.4$ & \\
\hline
\end{tabular}

* Significant p-value.

a Student's T-test was used. 


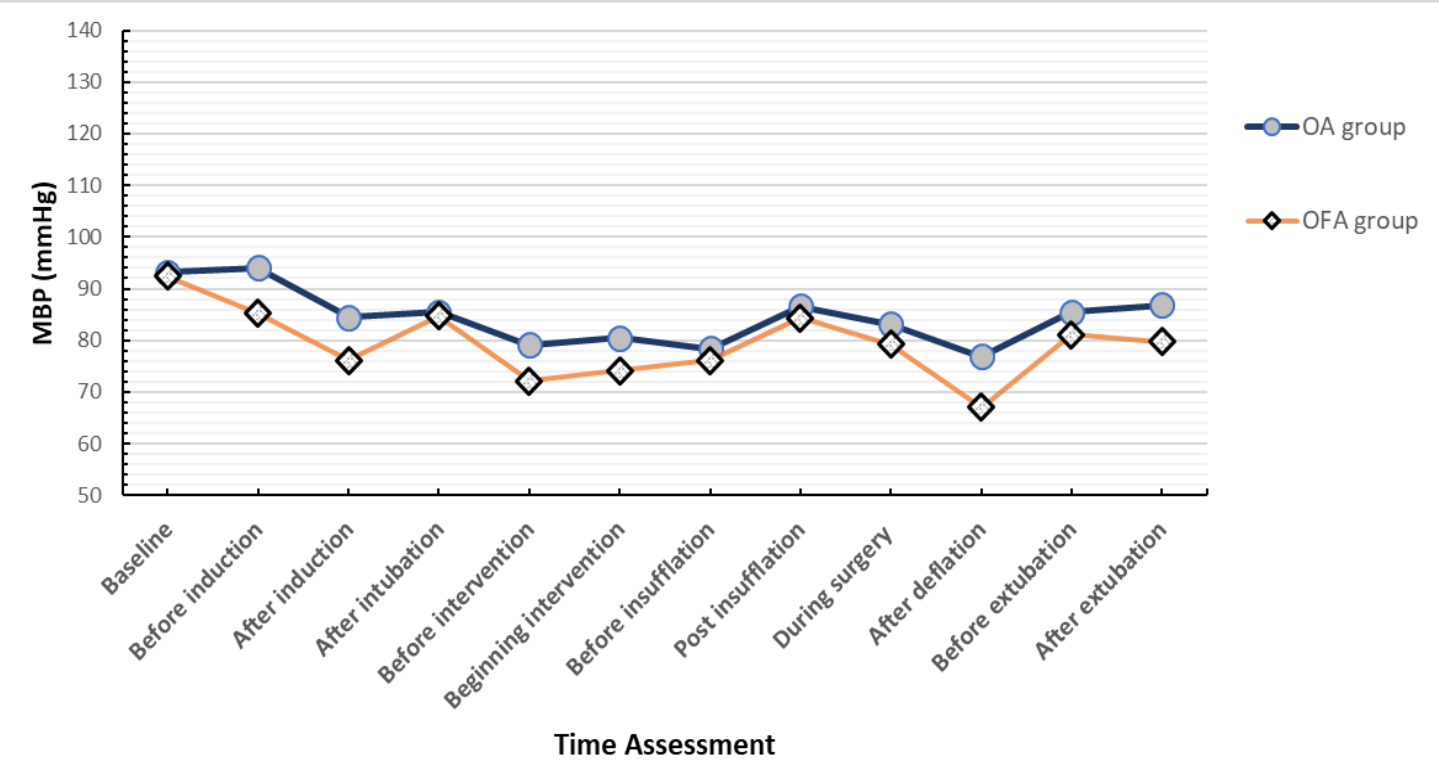

Figure (4) Intraoperative mean blood pressure changes for studied groups

Regarding intraoperative use of ephedrine:

The number of patients who needed intraoperative ephedrine was $10(32.3 \%)$ in the OA group and 13 $(41.9 \%)$ in the OFA group but this difference is not statistically significant as demonstrated in Table (6) Also, the table shows the stages of intraoperative ephedrine use in both groups.

Table (6) Number of patients with intraoperative ephedrine use in both groups

\begin{tabular}{|c|c|c|c|}
\hline & $\mathbf{O A}$ & OFA & p-value ${ }^{a}$ \\
\hline $\begin{array}{l}\text { Patients } \\
\text { needed IOP } \\
\text { ephedrine }\end{array}$ & $\begin{array}{l}10 \\
(32.3 \%)\end{array}$ & $\begin{array}{l}13 \\
(41.9 \%)\end{array}$ & 0.430 \\
\hline \multicolumn{4}{|l|}{ Stage of use: } \\
\hline $\begin{array}{l}\text { Before } \\
\text { induction }\end{array}$ & 0 & $4(12.9 \%)$ & \multirow{6}{*}{$<0.05^{*}$} \\
\hline $\begin{array}{l}\text { After } \\
\text { induction }\end{array}$ & 0 & $4(12.9 \%)$ & \\
\hline $\begin{array}{l}\text { Before } \\
\text { intervention }\end{array}$ & $\begin{array}{l}9 \\
(29.0 \%) \\
\end{array}$ & 0 & \\
\hline $\begin{array}{l}\text { During } \\
\text { surgery }\end{array}$ & $1(3.1 \%)$ & $5(16.1 \%)$ & \\
\hline After deflation & $1(3.1 \%)$ & $4(12.9 \%)$ & \\
\hline $\begin{array}{l}\text { After } \\
\text { extubation }\end{array}$ & $1(3.1 \%)$ & $5(16.1 \%)$ & \\
\hline
\end{tabular}

* Significant $p$-value. ${ }^{a}$ Chi-square test was used

Regarding the intraoperative use of rescue analgesia:

The number of patients in the OA group that needed intraoperative rescue analgesia was $22(70.9 \%)$ while in the OFA group no patient needed it as shown in Table (7) which also demonstrated the stages during which analgesia was administered. The mean of rescue analgesia used intraoperatively for OA group was $55.6 \pm 37.4 \mu \mathrm{g}$ and the median was $70 \mu \mathrm{g}$ with the highest dose of $100 \mu \mathrm{g}$.

Table (7) Number of patients with intraoperative rescue analgesia use

\begin{tabular}{|c|c|c|c|}
\hline & $\mathbf{O A}$ & OFA & p-value ${ }^{a}$ \\
\hline $\begin{array}{l}\text { Patients needed } \\
\text { IOP rescue } \\
\text { analgesia }\end{array}$ & $\begin{array}{l}22 \\
(70.9 \%)\end{array}$ & 0 & $<0.001^{*}$ \\
\hline \multicolumn{4}{|l|}{ Stage of use: } \\
\hline After intubation & $4(12.9 \%)$ & 0 & \multirow{10}{*}{$<0.05^{*}$} \\
\hline $\begin{array}{l}\text { Beginning of } \\
\text { intervention }\end{array}$ & $5(16.1 \%)$ & 0 & \\
\hline $\begin{array}{l}\text { Before } \\
\text { insufflation }\end{array}$ & $4(12.9 \%)$ & 0 & \\
\hline Post insufflation & $3(9.8 \%)$ & 0 & \\
\hline $\begin{array}{l}\text { During surgery at } \\
10 \mathrm{~min}\end{array}$ & $\begin{array}{l}17 \\
(54.8 \%)\end{array}$ & 0 & \\
\hline $\begin{array}{l}\text { During surgery at } \\
\text { 30min }\end{array}$ & $3(9.8 \%)$ & 0 & \\
\hline $\begin{array}{l}\text { During surgery at } \\
\mathbf{4 0} \mathrm{min}\end{array}$ & $5(16.1 \%)$ & 0 & \\
\hline $\begin{array}{l}\text { During surgery at } \\
50 \mathrm{~min}\end{array}$ & $8(25.8 \%)$ & 0 & \\
\hline After deflation & $4(12.9 \%)$ & 0 & \\
\hline Before extubation & $\begin{array}{l}12 \\
(38.7 \%)\end{array}$ & 0 & \\
\hline
\end{tabular}

Regarding postoperative assessment:

$=$ Postoperative heart rate and blood pressure in studied groups: 
The heart rate and systolic, diastolic and mean blood pressure readings postoperatively in the OFA group were lower than the OA group and this difference was statistically significant $(\mathrm{P}<0.001)$ as shown in Table (8).

Table (8) Postoperative heart rate and blood pressure in studied groups

\begin{tabular}{|c|c|c|c|}
\hline & OA & OFA & p-value ${ }^{a}$ \\
\hline Heart rate & $\begin{array}{l}105.8 \pm \\
13.4\end{array}$ & $\begin{array}{l}84.5 \pm \\
22.0\end{array}$ & $<0.001 *$ \\
\hline $\begin{array}{l}\text { Systolic blood } \\
\text { pressure }\end{array}$ & $\begin{array}{l}123.2 \pm \\
9.1\end{array}$ & $\begin{array}{l}109.0 \pm \\
7.0\end{array}$ & $<0.001^{*}$ \\
\hline $\begin{array}{l}\text { Diastolic } \\
\text { blood } \\
\text { pressure }\end{array}$ & $\begin{array}{l}75.9 \pm \\
9.2\end{array}$ & $\begin{array}{l}65.9 \pm \\
9.4\end{array}$ & $<0.001^{*}$ \\
\hline $\begin{array}{l}\text { Mean blood } \\
\text { pressure }\end{array}$ & $\begin{array}{l}91.3 \pm \\
14.8\end{array}$ & $\begin{array}{l}78.6 \pm \\
6.9\end{array}$ & $<0.001 *$ \\
\hline
\end{tabular}

* Significant p-value. $\quad$ a Student's T-test was used.

\section{Postoperative recovery state assessed by Aldrete score in studied groups:}

There was no difference between both groups as regards the postoperative Aldrete score. For Group OA (Median (IQR): 9 (9-10), Min-Max: $9-10)$ and Group OFA ((Median (IQR): $9(9-10)$, Min-Max: 9 -10) with $P$ value $(0.613)$.

\section{Postoperative pain level measured by VAS score in studied groups:}

The VAS score was higher in the OA group (ranged from $0-6$ ) compared to the OFA group (ranged from $0-4$ ) but this difference was not statistically significant $(\mathrm{p}=0.150)$.

\section{Postoperative analgesic consumption in studied groups:}

There were 7 patients $(22.6 \%)$ of OA group received additional postoperative analgesia (in form of fentanyl boluses) with mean of dose 78.6 $\pm 11.1 \mu \mathrm{g}$ (minimum $=65$, maximum $=100$ ) while in OFA group only 3 patients $(9.7 \%)$ needed additional analgesia and received it as infusion (of both ketamine and dexmedetomidine) with mean of duration $26.6 \pm 5.7$ min. $($ minimum $=20$, maximum $=30$ ) and this difference was statistically insignificant $(\mathrm{P}$ value $=$ 0.167). There was no significant difference also as regards the time of the first analgesic requirement in both groups. $(\mathrm{P}$ value $=0.882)$

Incidence of postoperative side effects and complications in studied groups

As illustrated in Table (9), the postoperative complications that were recorded were as follows:

There were 10 (32.3\%) patient from OA group had PONV compared to $3(9.7 \%)$ patients from OFA group indicating a significant increase in the incidence of PONV in OA group (P-value 0.033). There were 5 $(16.1 \%)$ patients from group OA who had shivering compared to $2(6.5 \%)$ patients from the OFA group, but this difference was statistically insignificant. While $6(19.4 \%)$ patients from the OFA group with sedation compared to no patient from the OA group. There was no report of respiratory depression or pruritis or any other complication or side effect in either group.

Table (9) Postoperative side effects and complications in studied groups

\begin{tabular}{|c|c|c|c|}
\hline & OA & OFA & p-value ${ }^{a}$ \\
\hline PONV & $10(32.3 \%)$ & $3(9.7 \%)$ & $0.033^{*}$ \\
\hline Sedation & 0 & $6(19.4 \%)$ & $0.024 *$ \\
\hline Shivering & $5(16.1 \%)$ & $2(6.5 \%)$ & 0.424 \\
\hline
\end{tabular}

\section{Postoperative duration of stay in PACU in studied groups}

Comparing the duration of postoperative stay in PACU in both groups, there was no statistically significant difference between both groups but was slightly higher for the OFA group than the OA group. As for the OA group, the mean was $14.0 \pm 11.1$ minutes and for OFA group was $16.4 \pm 7.8$ minutes. ( $\mathrm{p}$ value $=0.325)$.

\section{Length of hospital stay in the studied groups:}

Comparing the duration of hospital stay in both groups: Group OFA showed lower duration, as the mean was $176.2 \pm 31.3$ minutes, compared to the OA group in which the mean was $180.6 \pm 28.2$ minutes. However, this difference between groups was not statistically significant. $(\mathrm{P}$ value $=0.559)$.

\section{DISCUSSION}

Laparoscopic surgical procedures have various benefits to the patient in terms of decreased tissue damage, early ambulation, decreased hospital stay and reduced analgesic needs. However, the creation of pneumoperitoneum has its own disadvantages in terms of the adverse hemodynamic cardiovascular, respiratory, stress response and acid-base physiology. The increase in MAP and systemic vascular resistance (SVR) occurring immediately at the induction of pneumoperitoneum is suggestive of the involvement of the sympathetic nervous system ${ }^{\left({ }^{(}\right)}$. These hemodynamic responses are due to the increased release of catecholamines, vasopressin, or both ${ }^{(7,8)}$. Several modifications in technique have been tried to attenuate these responses. Various pharmacological agents are used to provide hemodynamic stability during pneumoperitoneum with varying success rates. Currently, the opioids are the basis of intra-operative pain management, which despite being effective, can result in numerous intra-operative and post-operative 
side effects which can also lead to a prolonged hospital stay and increased hospital costs ${ }^{(\mathbf{8}, \mathbf{9})}$.

These side effects are one of the main reasons why a multimodal anesthetic approach such as OFA is considered a safe solution to represents the avoidance of opioids in the treatment of pre, intra, and postoperative pain in an attempt to reduce opioidrelated complications without compromising the patient's comfort.

This comparative single-blinded study was designed to primarily compare OFA to the conventional general anesthesia (with opioid) regarding hemodynamic stability intraoperatively as a reflection of the adequacy of analgesia, speed of recovery, postoperative analgesia, discharge time from PACU and hospital LOS.

Regarding intraoperative heart rate, systolic, diastolic, mean blood pressures, statistical analysis showed that there is a significant difference between OA and OFA groups. While both groups maintained hemodynamical stability guided by the baseline readings, the OFA group showed lower readings compared to the OA group. These results are supported by other findings such as the need for rescue analgesics and for ephedrine boluses intraoperatively which are used to maintain intraoperative hemodynamic stability. The statistical analysis showed that the group OA had frequent use of rescue analgesics intraoperatively in comparison with OFA group which had no use of rescue analgesic but had more frequent use of ephedrine boluses, though there was no significant difference between OFA and OA groups in that variable, explaining the changes in hemodynamics.

The lower readings in hemodynamics in group OFA may be due to the sympatholytic effect of dexmedetomidine which is a highly selective $\alpha 2$ agonist that can cause significant bradycardia and hypotension. However, the reduction in hemodynamics was limited and was manageable to counteract by using ephedrine. Therefore, the study encountered the use of ketamine infusion along with dexmedetomidine which can have a cardiovascular stimulant effect that may limit the sympatholytic effect of dexmedetomidine.

These results were coherent with the findings in the double-blinded controlled study performed by Pestieau et al. ${ }^{(10)}$, in which participants undergoing tonsillectomy were randomized to receive one intravenous dose of fentanyl $\left(1 \mu \mathrm{g} \cdot \mathrm{kg}^{-1}\right.$ or $\left.2 \mu \mathrm{g} \cdot \mathrm{kg}^{-1}\right)$ or dexmedetomidine $\left(2 \mu \mathrm{g} \cdot \mathrm{kg}^{-1}\right.$ or $\left.4 \mu \mathrm{g} \cdot \mathrm{kg}^{-1}\right)$ immediately after endotracheal intubation. The researchers found that children treated with dexmedetomidine had lower heart rates and blood pressure readings compared with those treated with fentanyl. But, these changes were clinically welltolerated, they were resolved spontaneously, and they did not warrant pharmacologic intervention which was at odds with the present study but this may be due to the different dosing and route of administration, as in Pestieau's dexmedetomidine was given once in a single shot whereas in the present study it was given in a loading dose before induction followed by a maintenance continuous infusion throughout the surgery ${ }^{(10)}$.

Another study performed by Bakan $\boldsymbol{e t}$ al. ${ }^{(11)}$, in which patients scheduled for elective laparoscopic cholecystectomy were randomly allocated into two groups to have either opioid-free anesthesia with dexmedetomidine, lidocaine, and propofol infusions (Group DL) or opioid-based anesthesia with remifentanil, and propofol infusions (Group RF) both groups continue through total intravenous anesthesia (TIVA). The researchers found that heart rate and mean arterial pressure values after induction, at intubation and 1st, 4th, 7th and 10th $\mathrm{min}$ of pneumoperitoneum were significantly higher in Group DL. Group RF showed more patients requiring ephedrine to correct hypotension, and Group showed more patients requiring nitroglycerine to correct hypertension. Nitroglycerine use in Group DL was mostly at the beginning of the pneumoperitoneum ${ }^{(11)}$. These results may contradict the results of the present study, but it may be owed to the different methodology as Bakan's used TIVA while the present study we used inhalational anesthesia for better control on hemodynamics. Also, Bakan's study used lower dosing and infusion rates than the present study, as Bakan's used loading Dexmedetomidine dose of $(0.6 \mathrm{~g} / \mathrm{kg})$ and the maintenance infusion rate was $\mathrm{e}$ $(0.3 \mathrm{~g} / \mathrm{kg} / \mathrm{h})$ which, though provided rapid recovery in their results, it may be the cause of the higher readings of heart rate and mean $\mathrm{BP}$ and the reason why nitroglycerine was needed to maintain stability. Using a higher dose as was done in the present study can provide more hemodynamical stability.

Shalaby et al. ${ }^{(12)}$ also reached similar results to the present study. They sampled eighty patients who were scheduled for elective laparoscopic cholecystectomy and randomly divided them into two equal groups: (40 each). Non-opioid group received dexmedetomidine $(1 \mu \mathrm{g} / \mathrm{kg})$ over 10 minutes before induction of anesthesia then maintained by IVs infusion of $0.5 \mu \mathrm{g} / \mathrm{kg} / \mathrm{hr}$ until the end of surgery and Opioid group received fentanyl $(1.0 \mu \mathrm{g} / \mathrm{kg})$ over 10 minutes before induction of anesthesia then maintained by IV infusion of $0.4 \mu \mathrm{g} / \mathrm{kg} / \mathrm{hr}$. until the end of surgery. They concluded that there were no significant differences between the two groups regarding HR and MAP except after loading dose of the studied drugs, after intubation, after pneumoperitoneum, $15 \mathrm{~min}, 30 \mathrm{~min}, 45 \mathrm{~min}$, and 60 min after induction where it was lower in dexmedetomidine group than fentanyl group ${ }^{(\mathbf{1 2})}$. 
Although they used a different methodology, all came in agreement with the results of the present study. However, Shalaby's study did not factor in the intraoperative use of vasopressor or the rescue analgesia which can alter the results to a different conclusion.

Regarding postoperative pain management, there was no significant difference between both groups in VAS scores, the number of patients needed further analgesia or in the time for first analgesic requirement, however, the OFA group showed lower readings in hemodynamics postoperatively compared to OA group. It is believed that Dexmedetomidine may, in fact, have analgesic properties: One metaanalysis concluded that dexmedetomidine reduced early postoperative pain scores and opioid consumption when administered intraoperatively to patients receiving general anesthesia in mixed surgical cohorts ${ }^{(13)}$. However, this is still on debate and under investigation, the value of adding ketamine to dexmedetomidine has definite merits. ketamine was proved, at doses less than $0.5 \mathrm{mg} / \mathrm{kg}$, to reduce postoperative analgesic needs and this is especially seen in the opioid-tolerant patient ${ }^{(14)}$.

These results were consistent with the results of the study done by Walldén $\boldsymbol{e t}$ al. ${ }^{(15)}$, in which fifty patients (age, 19-69 years) undergoing day-case laparoscopic cholecystectomy were randomly assigned to receive either total intravenous anesthesia with propofol/remifentanil/rocuronium (TIVA; $\mathrm{n}=$ $25)$ or inhalational opioid-free anesthesia with sevoflurane/rocuronium (mask induction; GAS; $\mathrm{n}=$ 25). They found that There were no differences between the groups in maximal VAS scores for pain, also there was no significant difference in the need for opioid analgesics or the dose of opioid analgesics ${ }^{(15)}$.

Analogous to the findings of the present study, Tufanogullari et al. ${ }^{(16)}$, found that the readings in hemodynamics postoperatively were significantly higher in the OA group than the OFA group. As for Tufanogullari's, they enlisted eighty consenting ASA II-III morbidly obese patients in their study and randomly assigned them into 1 of 4 treatment groups: (1) control group received a saline infusion during surgery, (2) Dex 0.2 group received an infusion of 0.2 $\mathrm{g} / \mathrm{kg} / \mathrm{h} \mathrm{IV}$, (3) Dex 0.4 group received an infusion of $0.4 \mathrm{~g} / \mathrm{kg} / \mathrm{h} \mathrm{IV}$, and (4) Dex 0.8 group received an infusion of $0.8 \mathrm{~g} / \mathrm{kg} \mathrm{IV}$. Although the intraoperative hemodynamic values were similar in the four groups which were at odds with the results of the present study, arterial blood pressure values on admission to the PACU were significantly reduced in the Dex 0.2 , 0.4 , and 0.8 groups compared with the control group which came in agreement with the findings in the present study, as well as Tufanogullari's results regarding postoperative analgesic consumption and pain scores. They found that the amount of rescue fentanyl administered in the PACU was significantly less in the Dex 0.2, 0.4, and 0.8 groups versus the control group, although the PCA morphine requirements on postoperative days (PODs) 1 and 2 were not different among the four groups. Pain scores in the PACU, and on PODs 1, 2, and 7, in the three Dex groups were not different from the control group which came in agreement with the results of the present study ${ }^{(16)}$.

The present study also investigated the duration of stay in PACU and the incidence of side effects postoperatively, particularly the incidence of PONV which is very common after laparoscopic cholecystectomy. It was found that there was no significant difference between both groups regarding the time spent in PACU. These findings were supported by the same recovery scores in both groups as they showed no significant difference in modified Aldrete scores.

Regarding the incidence of side effects in the present study, there was a significant increase in the incidence of PONV in the OA group compared to the OFA group. Also, 6 patients (19.4\%) from the OFA group reported sedation compared to no patient from the OA group which was statistically significant. There was no incidence of other side effects or complications in both groups including (respiratory depression, pruritis, hypotension, bradycardia).

These results are in accordance with the results of a study done by Samuels $\boldsymbol{e t} \boldsymbol{a l} .{ }^{(17)}$, in which they reviewed all surgical cases by an anesthesiologist who changed his anesthesia regimen from opioid-sparing anesthesia (OSA) to OFA and compared groups of patients from the last 2 months of 2013 (OSA) and the last 2 months of 2015 (OFA) with a control group when that used conventional opioid anesthesia (OA) (17). Similar to the present study's results, they reported that patients in the OFA group experienced less nausea and vomiting than the other groups, also that both OA and OSA groups needed twice the dose of opioids in the PACU as the OFA group. However, they noted longer PACU duration in the OA group, which contradicts the results of the present study, but this could be attributed to factors other than the anesthesia regimen because of the retrospective nature of Samuel's study which did not consist of patient discharge criteria.

Bulow et al. ${ }^{(18)}$, also investigated in their study the duration of stay in PACU and reported no significant difference between the REM group which received remifentanil and DEX group which received dexmedetomidine, although extubation and orientation times were higher in DEX-anesthetized patients when compared with REM patients. These findings are in agreement with the present study however there is contradict it in the assessment of the frequency of side effects. Bulow's reported no 
significant difference between the REM and DEX groups in the incidence of side effects ${ }^{(\mathbf{1 8})}$. This can be owed to a low frequency of postoperative nausea and vomiting (PONV) after TIVA to begin with, which is in accordance with data in the literature ${ }^{(19)}$.

This contradiction was reported also by Walldén et al. ${ }^{(15)}$, who randomly assigned fifty patients (age, 19-69 years) undergoing day-case laparoscopic cholecystectomy to receive either TIVA

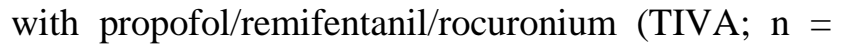
25 ) or inhalational OFA with sevoflurane/rocuronium (mask induction; GAS; $\mathrm{n}=25$ ). Although their results agreed with the present study that there were no differences between the groups in VAS scores for pain or the need for further postoperative opioid analgesics there were other conflicts. Walldén's noted that there were no statistically significant differences between the groups in the incidence of nausea, vomiting, PONV, but we cannot exclude the possibility that other perioperative factors may also have main impacts on early gastric emptying, and it is difficult to distinguish between all the factors involved ${ }^{(15)}$.

The present study also assessed the length of hospital stay, although it was reduced in group OFA in comparison to group OA, this difference was statistically insignificant. These findings were in agreement with the findings in Tufanogullari's study on the effect of dexmedetomidine infusion during laparoscopic bariatric surgery, where it was found that the quality of recovery scores and times to recovery of bowel function and hospital discharge did not differ among the four groups of study, three of which received different dosage of dexmedetomidine infusions compared to a control group ${ }^{(16)}$.

Santoso et al. (20), studied the link between postoperative pain control and LOS through testing the effectiveness of multimodal pain control protocol (MMPC) in comparison to an opioid agent solely using PCA. The results showed that the MMPC group reported lower LOS than the opioid only group using PCA. Although Santoso's did not directly assess postoperative pain score or morphine usage; patients receiving MMPC met the discharge criteria earlier than those who received morphine PCA alone, which suggests that MMPC is associated with faster and more effective pain control and that postoperative pain control indeed is linked to faster hospital discharge ${ }^{\mathbf{( 2 0 )}}$. These findings support the results of the present study as OFA group proved to manage postoperative pain as effectively as OA group and both groups showed no significant difference in VAS scores postoperatively which, in the light of Santoso's study, may explain why the LOS in the present study was not significantly different between both groups.

In summary, the study demonstrated that OFA can provide intraoperative hemodynamical stability and reduce the incidence of postoperative side effects (particularly PONV). It also is as effective as opioids in controlling postoperative pain and duration of stay in PACU and hospital LOS.

\section{CONCLUSION}

The study at hands showed that both OA and OFA could maintain intraoperative hemodynamic stability effectively although the OA group showed a higher need for intraoperative analgesia in comparison to the OFA group which did not require any rescue analgesics.

OFA also showed a reduction of incidence of PONV compared to group OA but neither group showed pruritis or respiratory depression.

Both OFA and OA showed no significant difference regarding postoperative VAS scores, analgesic consumption, discharge time from PACU or the hospital LOS.

Limitations of this study may reside in the type of patients included in the present study, who were classified as ASA class I or II, which limits the application of this protocol in practice settings with a lower patient comorbid burden. Specific populations of surgical patients that may be even more likely to benefit from OFA including, patients with obesity and/or obstructive sleep apnea, or chronic pain, should be targeted specifically in further studies.

We also recommend further studies on OFA to be tried on more complexed surgeries that require longer period of hospitalization, to allow better assessment of OFA effect on a longer recovery period and longer duration of hospitalization which were not possible to properly assess in the present study due to the nature of LC being a day case surgery.

\section{Conflict of Interest Statement:}

The authors declare that there are no conflicts of interest.

\section{Funding and Ethical Consideration:}

No Funding was obtained. The proposal was approved via the Ethical Review Committee of Faculty of Medicine of Al Azhar University (Assuit), before starting the study. Written informed consent was obtained from all recruited patients.

\section{REFERENCES}

1. Sacerdote $P$ (2012): Non-Analgesic Effects of Opioids : Mechanisms and Potential Clinical Relevance of OpioidInduced Immunodepression. Curr Pharm., 18(37):60346042.

2. Angst MS, Clark JD (2006): Opioid-induced Hyperalgesia A Qualitative Systematic Review. J Am Soc Anesthesiol., 104(3):570-587.

3. Bisgaard T, Klarskov B, Rosenberg J, Kehlet H (2001): Characteristics and prediction of early pain after laparoscopic cholecystectomy. Pain, 90(3):261-269.

4. Bisgaard $\mathbf{T}$ (2006): Analgesic Treatment after Laparoscopic CholecystectomyA Critical Assessment of 
the Evidence. Anesthesiol J Am Soc Anesthesiol., 104(4):835-846.

5. Mulier JP (2014): Why and how to give opioid-free anesthesia (OFA). The Bruges approach. In: American Society of Anesthesiologists Annual Meeting, New Orleans. New Orleans, http://www.researchgate.net/publication/278307444.

6. Larsen JF, Svendsen FM, Pedersen V (2004): Randomized clinical trial of the effect of pneumoperitoneum on cardiac function and hemodynamics during laparoscopic cholecystectomy. Br J Surg., 91(7):848-854.

7. Myre K, Rostrup M, Buanes T, Stokland O (1998): Plasma catecholamines and hemodynamic changes during pneumoperitoneum. Acta Anaesthesiol Scand., 42(3):343347.

8. Mann C, Boccara G, Pouzeratte Y, Eliet J, Serradel-Le Gal C, Vergnes C (1999): The relationship among carbon dioxide pneumoperitoneum, vasopressin release, and hemodynamic changes. Anesth Analg., 89(2):278-283.

9. Toyoyama H, Kariya N, Hase I, Toyoda Y (2001): The use of intravenous nitroglycerin in a case of spasm of the sphincter of Oddi during laparoscopic cholecystectomy. J Am Soc Anesthesiol., 94(4):708-709.

10. Pestieau SR, Quezado ZMN, Johnson YJ et al. (2011): High-dose dexmedetomidine increases the opioid-free interval and decreases opioid requirement after tonsillectomy in children. Can J Anesth Can d'anesthésie, 58(6):540-550.

11. Bakan M, Umutoglu T, Topuz U et al. (2015): Opioidfree total intravenous anesthesia with propofol, dexmedetomidine and lidocaine infusions for laparoscopic cholecystectomy: a prospective . Rev Bras Anestesiol., 65(3):191-199.

12. Shalaby M, Abdalla M, Mahmoud AS (2018): Nonopioid versus Opioid Based General Anesthesia Technique for Laparoscopic Cholecystectomy. Egypt $\mathbf{J}$ Hosp Med.,73(3):6206-6412.
13. Wang X, Liu N, Chen J, Xu Z, Wang F, Ding C (2018): Effect of Intravenous Dexmedetomidine During General Anesthesia on Acute Postoperative Pain in Adults. Clin J Pain, 34(12):1180-1191.

14. Kator S, Correll DJ, Ou JY, Levinson R, Noronha GN, Adams CD (2016): Assessment of low-dose I.V. ketamine infusions for adjunctive analgesia. Am J Health Syst Pharm., 73(5):22-9.

15. Walldén J, Thörn S-E, Lövqvist Å, Wattwil L, Wattwil M (2006): The effect of anesthetic technique on early postoperative gastric emptying: comparison of propofol-remifentanil and opioid-free sevoflurane anesthesia. J Anesth., 20(4):261-267.

16. Tufanogullari B, White PF, Peixoto MP et al. (2008): Dexmedetomidine Infusion During Laparoscopic Bariatric Surgery: The Effect on Recovery Outcome Variables. Anesth Analg., 106(6):1741-1748.

17. Samuels D, Abou-Samra A, Dalvi P, Mangar D, Camporesi EM (2017): opioid-free anesthesia results in reduced postoperative opioid consumption. https://scientonline.org/open-access/opioid-freeanesthesia-results-in-reduced-post-operative-opioidconsumption.pdf.

18. Bulow N, Barbosa N, Rocha J (2007): Opioid consumption in total intravenous anesthesia is reduced with dexmedetomidine: a comparative study with remifentanil in gynecologic video laparoscopic surgery. J Clin Anesth., 19(4):280-285.

19. Dershwitz M, Michalowski P, Chang Y, Rosow CE, Conlay LA (2002): Postoperative nausea and vomiting after total intravenous anesthesia with propofol and remifentanil or alfentanil: how important is the opioid? J Clin Anesth., 14(4):275-278.

20. Santoso JT, Ulm MA, Jennings PW, Wan JY (2014): Multimodal pain control is associated with reduced hospital stay following open abdominal hysterectomy. Eur J Obstet Gynecol Reprod Biol., (183):48-51. 